\title{
Effect of Longitudinal Reinforcement Ratio and Effective Depth on Shear Capacity of PVA Fiber High Strength RC Beams
}

\author{
Zhuowei Wang ${ }^{a}$, Yufeng Liao and Weilun Wang ${ }^{\text {b, * }}$ \\ School of Civil Engineering, Shenzhen University, Shenzhen 518060, P. R. China. \\ a 1223731542@qq.com, *, b wang_weilun@hotmail.com
}

\begin{abstract}
The study on the shear capacity of PVA(polyvinyl alcohol) fibre reinforced high-strength concrete beams without stirrups was carried out by 7 specimens, the influence of effective depth(d) and longitudinal reinforcement ratio( $\rho t)$ were investigated. The experimental results show that the shear capacity of the beam increases significantly with the increase of the effective depth and as the reinforcement ratio of the longitudinal reinforcement increases, the shear strength of the beam will increase, but the increase ratio gradually decrease. Though the comparative analysis of the experimental data with calculated values under 3 building codes, indicated that the normative underestimate the effective depth and longitudinal reinforcement ratio on influence of shear capacity, and longitudinal reinforcement ratio ought to be considered into GB.
\end{abstract}

Keywords: effective depth; increases significantly; effective depth.

\section{Introduction}

Compared with normal strength concrete, high-strength concrete is characterised by a high modulus of elasticity, as its composition of very low water-binder ratio and ultra-fine materials such as silica fume, the internal structure became more denser as well as the durability, lower creep and drying shrinking. With higher strength and the strength increases rapidly.Also it can reduce the crosssectional size of structural members, and improve the use area and effective space of the building as the unit density intensity value ( $\mathrm{fc} / \rho$ ) is large [1-3].Based on the above advantages, interest in highstrength concrete with compressive strengths of 50-100MPa has increased rapidly in the last twenty years. High-strength concrete has been used widely in offshore structures, low-level columns in highrise buildings, long-span bridges, and other highway structures[4].However, high-strength concrete has less ductility, more prone to premature cracking, leading to steel corrosion, freeze-thaw damage, etc.in the reinforced concrete structures, thus the capacity of the structure reduced[5].Polyvinyl alcohol(PVA) fibre has the characteristics of high strength, high modulus as well as higher chemical and physical resistance, abrasion resistance and has good bonding properties with substrates such as cement[6].Depending on the interfacial bonds between concrete and fibre, the energy consumption caused by fiber de-bonding, pulling-out and pulling-off can improve the ductility of concrete[7].Other experimental studies have indicated that with the addition of discrete fibre into high-strength concrete form fiber-reinforced concrete, the tensile strength ,bending strength and impact strength can be improved as well as the toughness of the concrete, thereby overcoming in various unfavorable factors of application of high-strength concrete[8-9].

Currently, the compressive strength of concrete has been increased to $80 \mathrm{MPa}$ in many major codes and standards such as GB50010-2010 [10], JSCE-2007 [11], ACI318-11 [12], etc. However, due to the lack of sufficient test data, the calculation of shear capacity of the high-strength concrete is simply expand based on the normal concrete code. In this study, the effective depth (d) and longitudinal reinforcement ratio ( $\rho t)$ are considered as the influence parameters, the shear strength of PVA fibrereinforced high-strength concrete beams, without web reinforcement were tested. Analysis of experimental values versus calculated values of the major codes and standards, the influences of the effective depth and longitudinal reinforcement ratio on the shear capacity of reinforced concrete beams were investigated. 


\section{Experiment}

\subsection{Beam size and Materials}

A total of 7 beams were tested, the design cube compressive strength of concrete was $80 \mathrm{MPa}$ (the mixture proportion is shown in Table 1), the shear-span effective depth was maintained at 3.0 with a volume fraction of PVA fiber of 1.5\%.All beams were rectangular cross section $150 \mathrm{~mm}$ wide. Four effective depth and four longitudinal reinforcements were employed to test the effectiveness of effective depth and longitudinal reinforcement on shear behavior. The test beams were placed 2 groups, four effective depth were used in B1, B2, B3 and B4, being 270,220,310 and 360mm respectively. The longitudinal reinforcement ratios for $\mathrm{B} 1, \mathrm{~B} 5, \mathrm{~B} 6$ and $\mathrm{B} 7$ were 2.33, 2.03, 2.65 and $2.82 \%$ respectively. The beams were provided with longitudinal bars on its' right side (the test zone), to prevent shear failure in the non-experimental zone, the left side of the beams were reinforced with $\phi 8 @ 100$ stirrups. Details of the test program were given in Fig 1, the specific parameters of the test beam are shown in Table 2.

The concrete was made with PII52.5(R) Portland cement produced by Jinyang Cement Plant, In line with national general silicate standards. The coarse aggregate is made of basalt gravel provided by Shenzhen Longming Sand Field and the strength of the parent rock is 160-200MPa, with a maximum size of $20 \mathrm{~mm}$. The fine aggregate is inactive quartz sand, and water purification before the experiment, water content composite standard requirements, the mud content is less than $1 \%$ simultaneously. The water used was Shenzhen tap water, which meets the relevant requirements of JGJ63-2006 for Concrete Water Standards. The mineral powder produced by Jinan Rongxingda Mineral Powder Factory, Shandong Province. Sika series Viscocrete 3300 high-range water-reducing admixture was used for improving the workability of the high strength concrete. The PVA fiber was the Japanese Krary Group's type KURALON KII, and fiber were $12 \mathrm{~mm}$ long with a diameter of $0.04 \mathrm{~mm}$. The elastic modulus of the PVA fibers were $40 \mathrm{GPa}$, and ultimate tensile strength was $1600 \mathrm{MPa}$ with $5 \%$ elongation.

Table 1. Mixture properties

\begin{tabular}{|c|c|c|c|c|c|c|c|}
\hline \multirow{2}{*}{$\begin{array}{l}\text { Concrete } \\
\text { strength }\end{array}$} & \multicolumn{7}{|c|}{ Unit quantity $\left(\mathrm{kg} / \mathrm{m}^{3}\right)$} \\
\hline & $\begin{array}{c}\text { Water- binder } \\
\text { ratio }\end{array}$ & Cement & $\begin{array}{l}\text { Mineral } \\
\text { powder }\end{array}$ & Sand & $\begin{array}{c}\text { Coarse } \\
\text { aggregate }\end{array}$ & $\begin{array}{c}\text { Super } \\
\text { plasticiser }\end{array}$ & Defoamer \\
\hline $\mathrm{C} 80$ & 0.28 & 400 & 100 & 800 & 1200 & 12 & 1 \\
\hline
\end{tabular}

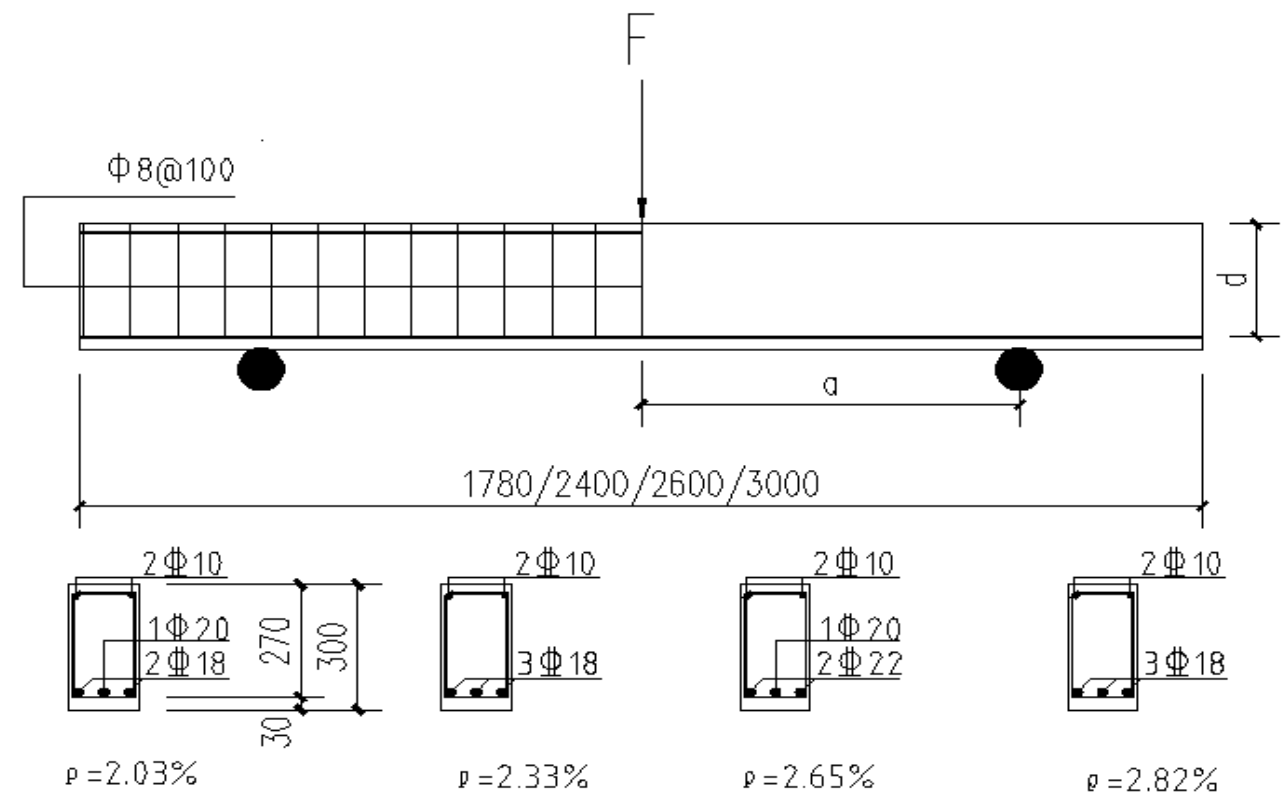

Fig 1. Details of test beams 
Table 2. Test beam parameters and shear test results

\begin{tabular}{ccccccc}
\hline \multirow{2}{*}{ Beam ID } & $\begin{array}{c}\rho_{t} \\
(\%)\end{array}$ & $\begin{array}{c}d \\
\mathrm{~mm}\end{array}$ & $\begin{array}{c}f_{\text {cuk }} \\
\mathrm{Mpa}\end{array}$ & $\begin{array}{c}f_{c}{ }^{\prime} \\
\text { Mpa }\end{array}$ & $\begin{array}{c}f_{t} \\
\text { Mpa }\end{array}$ & $\begin{array}{c}V_{\text {exp }} \\
\mathrm{kN}\end{array}$ \\
\hline B1 & 2.33 & 270 & 65.7 & 59.13 & 3.95 & 77.3 \\
B2 & 2.33 & 220 & 65.7 & 59.13 & 3.95 & 70.8 \\
B3 & 2.33 & 310 & 65.7 & 59.13 & 3.95 & 100 \\
B4 & 2.33 & 360 & 83.3 & 74.97 & 4.50 & 124.5 \\
B5 & 2.03 & 270 & 65.1 & 58.59 & 3.93 & 80 \\
B6 & 2.65 & 270 & 65.1 & 58.59 & 3.93 & 93.3 \\
B7 & 2.82 & 270 & 65.1 & 58.59 & 3.93 & 94.3 \\
\hline
\end{tabular}

\subsection{Test Method and Observed Behavior}

The test setup include a loading and a data acquisition system. The beams were tested under a concentrated load acting at mid-span, which was applied by $2000 \mathrm{KN}$ hydraulic jack. In order to measure the strain of the longitudinal bars, strain gauges was placed at the longitudinal bars which at the midpoint of the beam, at the midpoint of the shear span and at the support. Simultaneously, a strain gauge is placed at intervals of $50 \mathrm{~mm}$ in the beam span to measure the strain distribution of the beam span and the depth of the concrete compression zone. And to measure the displacement of the test beam, three displacement meters were placed at the span of beam and at the support.

During the loading process, the specimen first produces a curved crack at the beam span, which is short in length and appears both sides with the beam span, the load is small at this point, and as the load increases, the length of the crack increase but the growth is limited. New cracks develop little after a period of bending cracks, when the load is increased, after a small crack appears in the diagonal line between the beam support and the span, the crack will develop rapidly in a short time and extend to the vicinity of the loading point, the width of the crack increases rapidly simultaneously. And several parallels inclined crack appeared on the both sides of the main crack. Figure 2 is the inclined crack of beam B2 and the amplified crack morphology. It can be seen that the bonding properties of fiber and concrete are better, a part of fibers are dispersed in the crack without being pulled off, the coarse aggregate at the crack is completely split and the crack surface is smoothly.

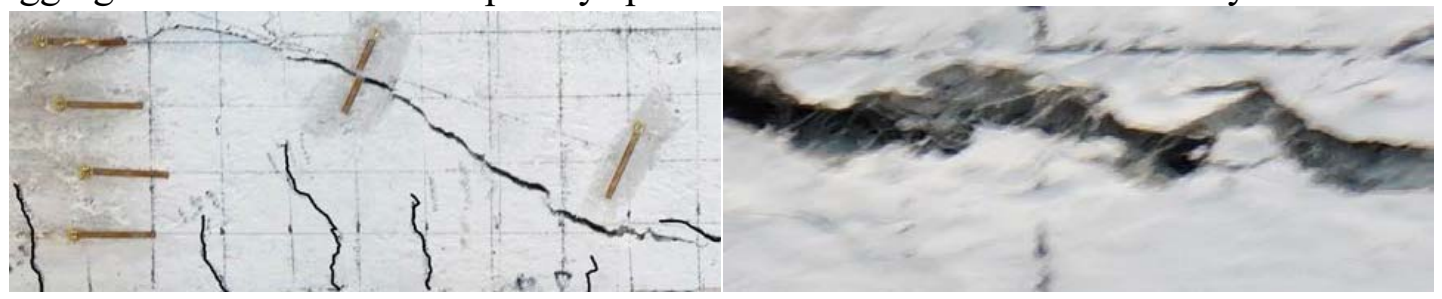

Fig 2. Beam B2 crack pattern

\section{Result and Analysis}

\subsection{Test Results}

Fig 3 shows the load-deflection curve of the test beams when the effective depth of the section changes. For beam without web reinforcement, with the effective depth increase, the width of the incline crack increase, the aggregate interlock force between cracks is weakened, causing the tensile stress in the cracking zone near the cracked end weakened and reduced the ability of the shear stress transmission. Also as the cross-sectional size increases, the size and aggregate particle size ratio increase accordingly, the shear slip surface become smoother and the action of aggregate interlock become reduced. However,it can be seen from figure 3 that the shear capacity increased as the effective depth increased. Compared beam B2 $(d=220 \mathrm{~mm})$ with beam B4 $(d=360 \mathrm{~mm})$, the shear capacity increased from $70.8 \mathrm{kN}$ to $124.5 \mathrm{kN}$, increased by nearly $76 \%$.Figure 4 shows the loaddeflection curve of the specimens when the longitudinal reinforcement ratio changes. All the longitudinal reinforcements in the specimens did not yield, it can be seen that the shear capacity 
increased with the increase of the reinforcement and the extent of growth will gradually decrease. Compared beam B5 with B6, the reinforcement ratio increased from $2.03 \%$ to $2.65 \%$, the shear capacity increased nearly $17 \%$,but compared beam B6 with B7, the reinforcement ratio changed from $2.65 \%$ to $2.82 \%$, the shear capacity only increased $1 \%$.And when the longitudinal reinforcement ratio is large, the deflection is small as the specimen fracture, and the brittleness characteristics becomes more significant.

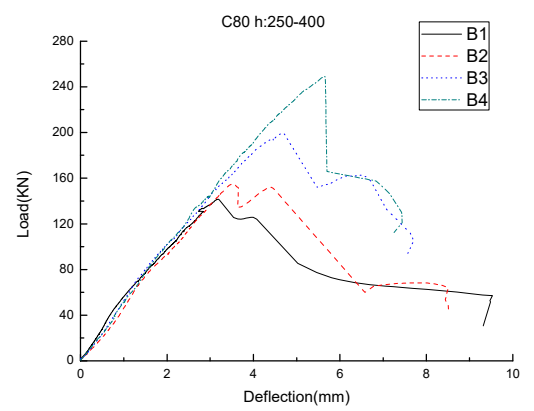

Fig 3. Load-deflection when d changes

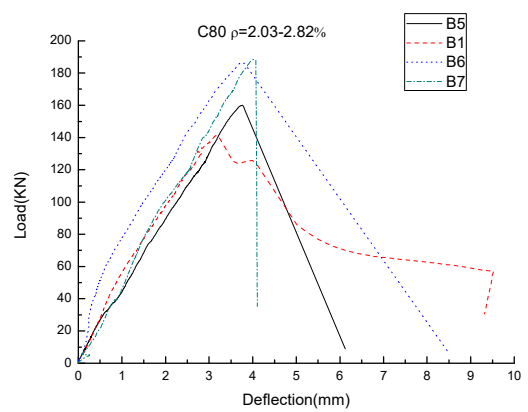

Fig 4. Load-deflection when $\rho_{t}$ changes

\subsection{Test Analysis}

There are many theoretical methods for calculating $\mathrm{RC}$ beams without web reinforcement, such as elastic theory method, plastic theory method, truss method and nonlinear theory method. This experiment further evaluates the applicability of national building codes by comparing the experimental values with the calculated values. The equations proposed for calculating the shear strength of beams without web reinforcement in GB5010-2010, ACI318-11 and JSCE2007, are expressed below:

$$
\begin{aligned}
V c & =\frac{1.75}{\lambda+1.0} f_{t} b h_{0} & \text { GB5010-2010 } \\
V c & =\left(0.16 \sqrt{f_{c}^{\prime}}+17.2 \rho_{t} \frac{V_{u} d}{M_{u}}\right) b_{w} d & \text { ACI3 } 18-11 \\
V_{c} & =0.20 \sqrt[3]{f_{c}^{\prime}} \sqrt[4]{1 / h_{0}} \sqrt[3]{100 \rho_{t}}(0.75+1.4 / \lambda) b h_{0} & \text { JSCE2007 }
\end{aligned}
$$

Where $\mathrm{Vc}$ is the shear capacity of reinforced concrete beams without web reinforcement; bw is the width of beam; $d$ is the effective depth of beam; $\rho t$ is the longitudinal reinforcement ratio; $V u$ and $\mathrm{Mu}$ are the shear and moment values at the critical section, respectively; $\mathrm{fc}^{\prime}$ is the cylinder concrete strength, $\mathrm{ft}$ is the tensile strength of concrete, fcub is the cube concrete strength, $\mathrm{fc}^{\prime}=0.9 \mathrm{fcub}$ [13], $\mathrm{ft}=0.395$ fcub0.55 [10].

It can be seen from the above-mentioned national building codes that the effective depth $\mathrm{d}$ is an important influence factor affecting the shear capacity of the RC beam without web reinforcement. Fig 5 is the effect of shear strength on specimen when the effective depth $d$ is changed. The shear capacity of the beam increases with the increase of the effective depth, which is consistent with the trend of the national building codes calculation results. The shear capacity ratio (experimental/predicted) of the different methods when effective depth d changed are shown in Fig6 With the increase of the effective depth, the current national methods show a trend of underestimating the shear capacity. Owing to the small effective depth of the test beam, the size effect is not significant. Compared with the other two methods, GB can better reflect the impact of shear capacity when effective height is in the range of of $220-360 \mathrm{~mm}$. 


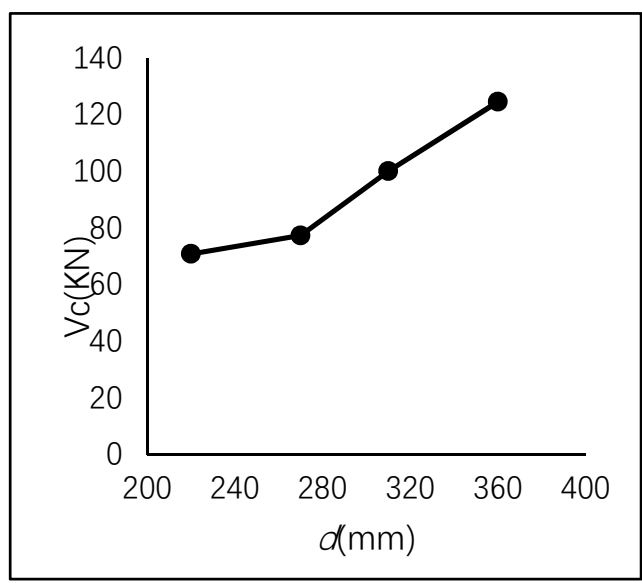

Fig 5. Relationship between $\mathrm{d}$ and $\mathrm{V}_{\mathrm{c}}$

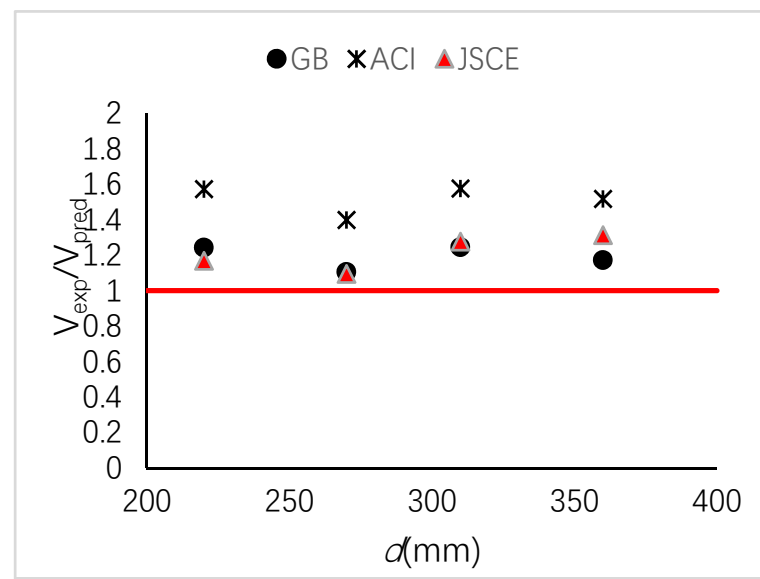

Fig 6. Relationship between $\mathrm{d}$ and $\mathrm{V}_{\mathrm{exp}} / \mathrm{V}_{\text {pred }}$

The longitudinal reinforcement ratio is also an important factor affecting the shear capacity of RC beams without web reinforcement. As the reinforcement ratio of the longitudinal reinforcement increases, the dowel action between the concrete and the longitudinal reinforcement will be strengthened, it can better restrain the development of cracks, increase the shear strength transfer between the Interfacial interaction between incline cracks and the depth of the concrete shear zone increase, thus the shear capacity of the specimen is correspondingly improved, is well shown in the Fig 7.The experimental values obtained under different reinforcement ratios are higher than the predicted values , and with the increase of the longitudinal reinforcement ratio, the increasing trend of the shear capacity is gradually decreasing, therefor it can also indicate the existence of the maximum reinforcement ratio. The influence of the longitudinal reinforcement is not considered in the GB, for better reflect the influence of the longitudinal reinforcement ratio on the shear capacity, the GB needs to be revised.

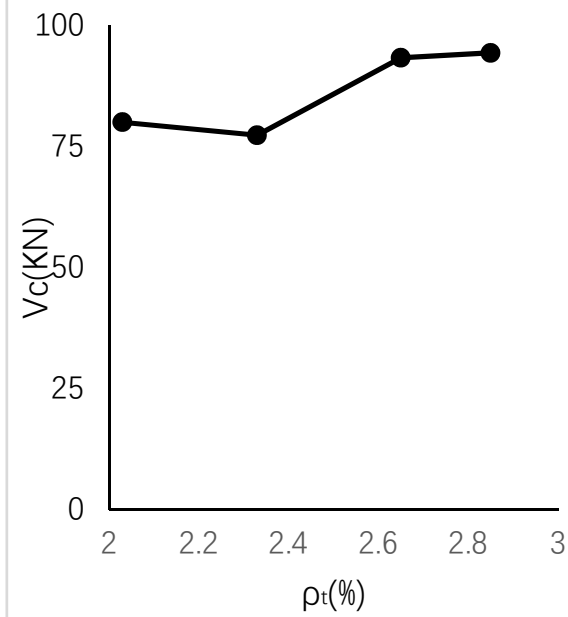

Fig 7. Relationship between $\rho_{\mathrm{t}}$ and $\mathrm{V}_{\mathrm{c}}$

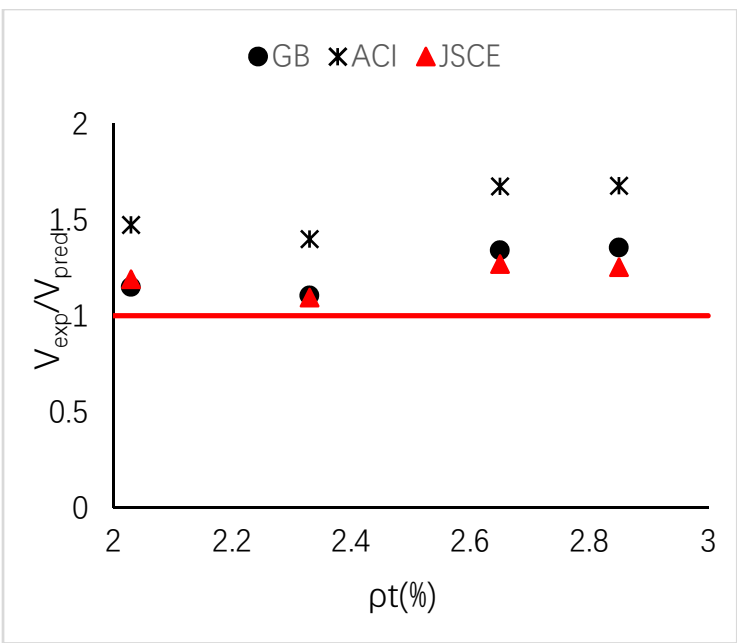

Fig 8. Relationship between $\rho_{\mathrm{t}}$ and $\mathrm{Vexp} / \mathrm{V}_{\text {pred }}$

\section{Conclusion}

In this study, shear tests were conducted on the PVA (polyvinyl alcohol) fibre reinforced highstrength concrete beams without stirrups. As the increase of the effective depth, the shear capacity of specimen is increased significantly. Owing to the small effective depth of the test beam, the size effect is not significant, the effective depth of the beam need to increase to further study the size effect, and current GB, ACI and JSCE methods all show a trend of underestimating the shear capacity. With the longitudinal reinforcement ratio increase, the dowel action become significant, the shear capacity is improved, but the increasing trend of the shear capacity is gradually decreasing. In order to better reflect the influence of the longitudinal reinforcement ratio on the shear capacity of the beam, the GB needs to be revised. 


\section{Acknowledgments}

This work was financially supported by the Natural Science Foundation of China (51378312).

\section{References}

[1]. Campione, G., Monaco, A., \& Minafò, G. (2014). Shear strength of high-strength concrete beams: modeling and design recommendations. Engineering Structures, 69(9), 116-122.

[2]. Bo Xu Houssam, A. Toutanji .Impact resi- stance of poly (vinyl alcohol) fiber re- inforced highperformance organic agg- regate cementitious material. [J]Cement and Concrete Research 40(2010) 347-351.

[3]. Sameer Hamoush, Taher Abu-Lebdeh, Toney Cummins. Deflection behavior of concrete beams reinforced with PVA micro-fibers. [J]Construction and Building Materials 24(2010)2285-2293.

[4]. AG Fallis, J. M. Concrete: microstructure, properties, and materials. New York: McGraw-Hill, 2006. 659 p.

[5]. O.Kayali, M. N. Haque. Some characteris- tics of high strength fiber reinforced lightweight aggregate concrete. [J] Cem- ent \& Concrete Composites 25(2003)207-213

[6]. L. Yue, Science and Technology of Overseas Building Materials 28 (1), 15-18 (2007).

[7]. J. Rui, X. Shilang and J. Jinqing, China Civil Engineering Journal 40 (8), 54-60 (2007)[8].C.S. Poon, Z.H. Shui, L. Lam. Compressive behavior of fiber reinforced high-performance concrete subjected to elevated temperatures. [J] Cement and Concrete Research 34 (2004) 2215-222

[8]. Shasha. Wang, Mi-Hong Zhang. Mechanical behavior of fiber-reinforced high-strength concrete subjected to high strain-rate compressive loading. [J]Construction and Building Materials 31 (2012)1-11

[9]. GB50010-2010. Code for design of concrete structures[S]. (in Chinese).

[10]. ACI318-2011. Building code requirement for structural concrete[S].

[11]. JSCE-2007. Standard specification for concrete structure, design[S]. (In Japanese).

[12]. Wille K., Naaman A. E., Parra-Montesinos G. J.,"Ultra-High Performance Concrete with Compressive Strength Exceeding $150 \mathrm{MPa}$ (22ksi): A Simpler Way," ACI Materials Journal, Vol.108. 2011, pp. 46-54. 